\title{
Analisis Sistem Antrian Pada Proses Pelayanan Konsumen di Rumah Makan
}

\author{
Hendra Nurjaya Al-Kholis ${ }^{1}$, Ellysa Nursanti ${ }^{2}$, Thomas Priyasmanu ${ }^{3}$ \\ 1,3Program Studi Teknik Industri S1, Institut Teknologi Nasional Malang \\ ${ }^{2}$ Program Studi Teknik Industri S2, Pascasarjana, Institut Teknologi Nasional Malang \\ *E-mail : hendrasimo95@gmail.com
}

\begin{abstract}
Abstrak
Antusias warga malang terhadap Rumah Makan sangat tinggi hal ini membuat Rumah Makan tidak pernah sepi oleh pengunjung sehingga mengakibatkan antrian. Tujuan penelitian ini untuk mengevaluasi kinerja sistem antrian stasiun pelayanan di Rumah Makan sehingga diperoleh penurunan jumlah antrian konsumen. Metode yang digunakan adalah metode simulasi dengan software Arena 10.0 Pengamatan dilaksanakan pada jam 12.00-24.00 untuk mendapatkan data waktu antar kedatangan dan waktu antar pelayanan. Pengukuran waktu menggunakan bantuan stopwatch. Berdasarkan hasil analisa kondisi eksisting, nilai Queue Waiting Time berkisar antara 0-1027 detik, Queue Number Inqueue berkisar antara 0-20 orang, Utilization berkisar antara 0.47\%-1\% dan Work In Process 1-21 orang. Berdasarkan hasil beberapa skenario yang telah dirancang dan dijalankan dengan bantuan process analyzer software ARENA 10.0 dipilih skenario 2. Pada skenario 2 mengasumsikan penambahan satu fasilitas stasiun pelayanan. Maka model antrian yang cocok adalah Multi ChannelSingle Phase (M/M/2) ; (FCFS) dimana terdapat fasilitas 2 stasiun pelayanan pada kondisi ramai jam 14.00-16.00, 18.00-22.00 dan jam 16.00-18.00 pada hari sabtu dan minggu. Penambahan stasiun, dapat mmenurunkan antrian menjadi Queue Waiting Time berkisar antara 0-18 detik, nilai Queue Number Inqueue 1 orang, nilai Utilization berkisar antara 0.37-0.68 \% dan nilai Work In Process berkisar antara 1-5. Sehingga dapat dikatakan bahwa skenario 2 menurunkan jumlah antrian $89 \%$.
\end{abstract}

Kata Kunci: Arena, Antrian, Simulasi, Stasiun Pelayanan.

\section{Pendahuluan}

Antrian merupakan suatu fenomena yang dihadapi konsumen pada industri jasa dan dunia usaha (bisnis). Antrian ialah suatu garis tunggu dari nasabah (satuan) yang memerlukan layanan dari satu atau lebih pelayan (fasilitas layanan) [1]. Setiap industri jasa dituntut untuk menjalankan sistemnya dengan cara meningkatkan efektifitas dan efisiensi proses dalam segi waktu. Agar dapat mengelola sistem stasiun pelayanan dengan benar, maka digunakan peralatan-peralatan modern yang berguna mempercepat dan mempersingkat pelayanan antrian, sehingga perusahaan dapat melayani konsumen dengan baik. Jasa adalah layanan aktivitas yang tidak memiliki, tidak bisa diraba dan tidak terlihat oleh mata yang diberikan dari satu pihak kepada pihak lain. Misalnya, keramahan dari seorang pramugari tidak dapat dilihat tetapi dapat dirasakan oleh penumpang [2]

Melalui simulasi yang dilakukan maka dapat dilihat ukuran kinerja dari sistem yang diamati yaitu sistem antrian di stasiun pelayanan Rumah Makan sehingga akan diperoleh output berupa usulan perbaikan dalam hal pelayanan agar pelayanan yang diberikan pada konsumen dapat dimaksimumkan. Simulasi adalah kegiatan mereproduksi perilaku sistem, menggunakan model yang menggambarkan atau merepresentasikan proses dari sistem nyata yang bersangkutan [3].

Tujuan dari penelitian ini adalah untuk mengevaluasi kinerja sistem antrian stasiun pelayanan di Rumah Makan sehingga diperoleh penurunan jumlah antrian konsumen.

Tingkat kedatangan konsumen Rumah Makan sangat tinggi sehingga mengakibatkan panjangnya antrian pada jam-jam tertentu dan hanya terdapat 1 stasiun pelayanan yang digunakan 
untuk melayani konsumen yang meliputi proses pemesanan menu dan transaksi pembayaran sehingga membuat konsumen untuk mendapatkan pelayanan dibutuhkan waktu yang lama. Berdasarkan hasil pengamatan nilai QWT berkisar antara 0-1027 detik, QNI berkisar antara 0-20 orang, Utilization berkisar antara $0.47 \%-1 \%$ dan WIP $1-21$ orang.

\section{Metodologi Penelitian}

\section{Karakteristik Sistem Antrian}

Komponen karakteristik bagi sebuah sistem pelayanan yaitu Ukuran populasi, perilaku kedatangan, pola kedatangan. Pada Rumah Makan displin antrian yang digunakan adalah First Come First Served (FCFS) atau First In First out (FIFO), dimana pelanggan yang datang lebih dulu akan dilayani lebih dulu. Jenis sistem antrian adalah Single Channel-Single Phase yaitu hanya ada satu jalur antrian dan hanya terdapat satu fasilitas pelayanan (server) [4].

\section{Struktur Antrian}

Ada dua model struktur antrian dasar yang digunakan dalam penelitian ini yaitu :

1. Single Channel-Single Phase

Single Channel berarti bahwa hanya ada satu jalur untuk memasuki sistem pelayanan atau ada satu pelayanan.

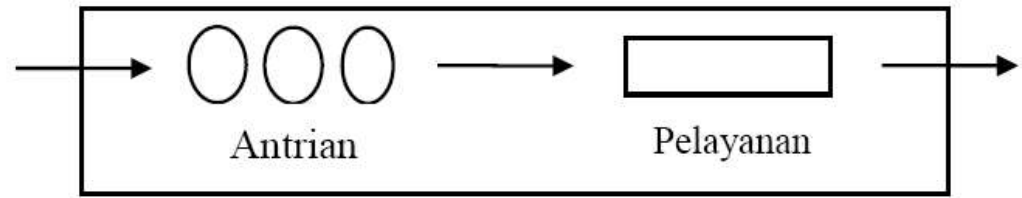

Gambar 1. Model Single Channel Single Phase

\section{Multi Channel Single Phase}

Sistem Multi Channel Single Phase terjadi ketika dua atau lebih fasilitas pelayanan dialiri oleh antrian tunggal.

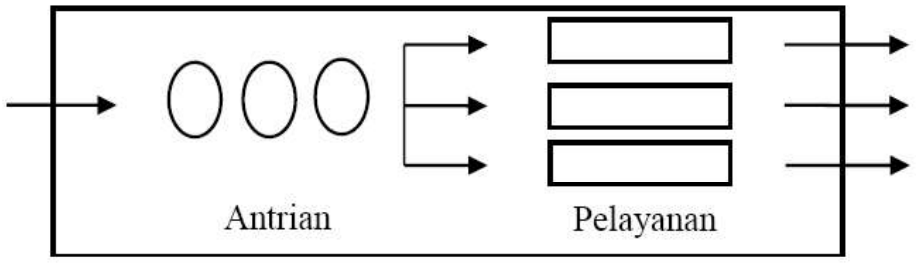

Gambar 2. Model Multi Channel Single Phase

Simulasi adalah kegiatan mereproduksi perilaku sistem, menggunakan model yang menggambarkan atau merepresentasikan proses dari sistem nyata yang bersangkutan [5].

Kelton [6] arena adalah sebuah program penyusun model dan juga merupakan simulator. Arena merupakan kombinasi antara kemudahan pemakaian yang dimiliki high level program dan fleksibilitas/kelenturan yang menjadi ciri general purpose simulation language. Ukuran kinerja sebuah sistem antrian dapat diketahui dari Rata-rata waktu tunggu yang dihabiskan pelanggan dalam antrian, jumlah pelanggan rata-rata dalam sistem, rata-rata jumlah pelanggan yang belum selesai diproses pada sistem antrian dan faktor utilisasi sistem [7]

Penelitian dilakukan di rumah makan yang berlokasi di Jl. Soekarno Hatta-Malang. Penelitian dilakukan selama 7 hari, yaitu pada hari Senin-Minggu pada tanggal 9-15 Januari 2017 pukul 12.0024.00 WIB. Data diambil langsung melalui proses pengamatan (observasi). Data tersebut berupa data waktu antar kedatangan pelanggan dan data waktu antar pelayanan konsumen pada stasiun pelayanan. Pengukuran waktu dengan menggunakan bantuan stopwatch.

Tahap-tahap penelitian yang dikerjakan pada stasiun pelayanan antara lain : 
1. Melakukan identifikasi sistem antrian stasiun pelayanan

2. Memodelkan sistem antrian stasiun pelayanan

3. Mengumpulkan waktu antar kedatangan dan waktu antar pelayanan

4. Analisis simulasi model awal sistem antrian pada stasiun pelayanan dengan model a (M/M/1) single channel-single phase.

5. Memberikan usulan perbaikan dengan merancang skenario-skenario perbaikan dengan bantuan Process Analyzer Software Arena 10.0

6. Perbandingan hasil analisis kondisi eksisting dan kondisi usulan perbaikan

7. Evaluasi hasil / evaluasi

Tahapan penelitian ini dapat dilihat pada diagram alir seperti pada gambar 3.

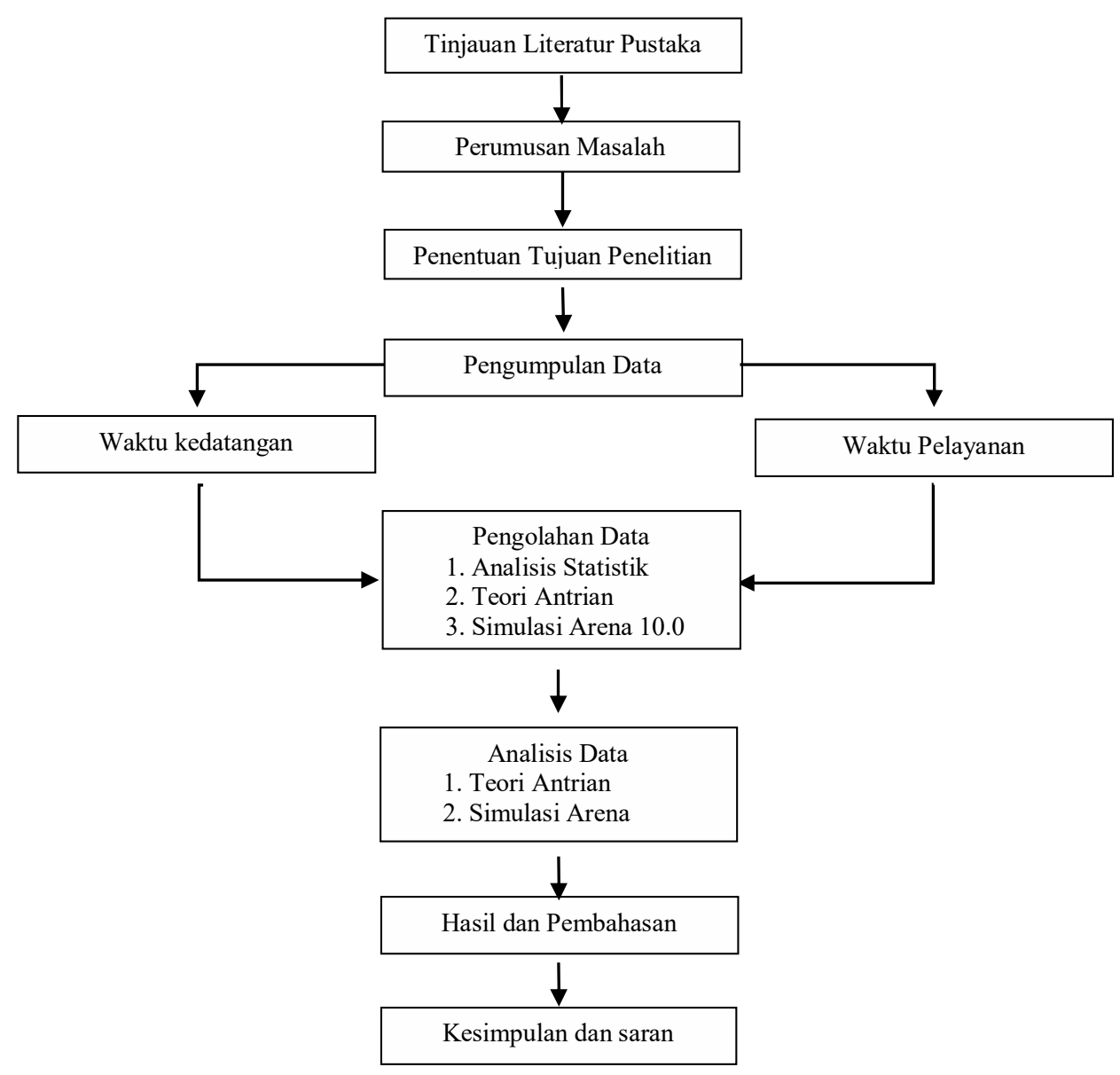

Gambar 3. Diagram Alir Penelitiaan

Kondisi Eksisting (Awal)

\section{Hasil dan Pembahasan}

Rumah Makan hanya terdapat satu fasilitas stasiun pelayanan dengan struktur model antrian

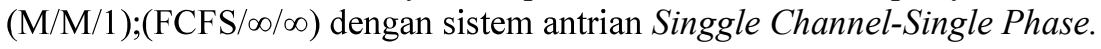




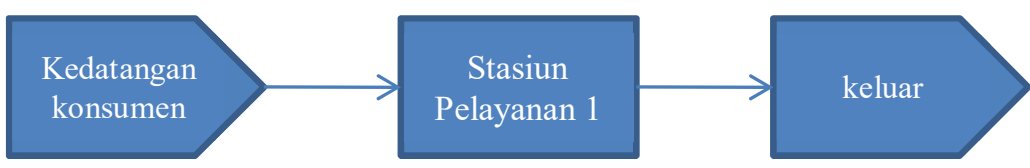

Gambar 4. Simulasi arena pada kondisi eksisting

Pada gambar 4 menggambarkan mekanisme sistem antrian yang terjadi dimulai dari pelanggan yang datang memasuki waiting line (garis tunggu antrian), lalu pelanggan menunggu dan mendapatkan pelayanan. Sistem antrian pada rumah makan terdapat satu fasilitas pelayanan kasir. Disiplin antrian yang digunakan adalah first come first served, dimana didalam sistem ini pelanggan yang datang lebih dahulu akan mendapatkan giliran pelayanan terlebih dahulu dan model antrian yang digunakan single channel-single phase yaitu hanya ada satu jalur antrian dan hanya terdapat satu fasilitas pelayanan.

Number In merupakan jumlah pelanggan yang masuk pada proses antrian, sedangkan Number Out merupakan jumlah pelanggan tersebut sudah selesai mendapatkan pelayanan. Queue Waiting Time (QWT) menunjukkkan rata-rata waktu tunggu pada saat mengantri untuk diproses dengan mendapatkan pelayanan dari stasiun pelayanan, sedangkan Queue Number Inqueue (QNI) menunjukkan rata-rata banyaknya pelanggan yang sedang mengantri pada sistem antrian. Work In Process (WIP) menunjukkan rata-rata jumlah pelanggan yang belum selesai diproses pada sistem antrian. Keadaan ini terjadi ketika pelanggan sudah masuk kedalam sistem antrian dan pelanggan tersebut sedang menerima pelayanan oleh stasiun pelayanan. Utilization menunjukkan nilai Utilization atau daya guna pada fasilitas pelayanan konsumen. Suatu model simulasi yang baik dapat dilihat berdasarkan nilai Utilization resources di setiap work station, nilai Utilization didapatkan dari hasil output software simulasi yang digunakan. Utilization memiliki rentang nilai dari 0 hingga 1, nilai mendekati 0 berarti resource pada work station tersebut terlalu menganggur dan sebaliknya jika mendekati 1 berarti resource pada work station terlalu sibuk. Nilai Utilization yang terbaik adalah yang terdapat dalam rentang 0,5 sampai 0,7 [8].

Simulasi model antrian dilakukan dengan bantuan software Arena untuk menggambarkan aliran kerja yang terjadi pada stasiun pelayanan dan untuk mengetahui waktu antrian, tingkat kesibukan yang terjadi pada sistem tersebut. Berdasarkan hasil analisa simulasi arena 10.0 pada kondisi eksisting dengan nilai rata-rata Queue Waiting Time berkisar antara 0-1027 detik, rata-rata Queue Number Inqueue berkisar antara 0-20, rata-rata Utilization berkisar antara $0,47-1 \%$ dan rata-rata Work In Process berkisar antara 1-21 orang dengan antrian yang terjadi pada pada hari Senin sampai Jum'at jam 14.00-16.00 dan 18.00-22.00, Sabtu jam 16.00-22.00 dan Minggu jam 14.00-22.00 nilai Queue Waiting Time, Queue Number Inqueue, Utilization dan nilai Work In Process sangat tinggi, dimana nilai ratarata nilai Queue Waiting Time berkisar antara 153-1027 detik, rata-rata Queue Number Inqueue berkisar antara 3-20 orang, rata-rata utilization berkisar antara 0,97-1\% dan rata-rata Work In Process berkisar antara 4-21 orang, maka di perlukan usulan perbaikan sistem pada jam-jam tersebut. Apabila pelanggan yang masuk kedalam sistem antrian banyak tetapi yang keluar dari sistem antrian sedikit, maka keadaan tersebut dikatakan belum optimal karena mengalami proses mengantri yang cukup lama dengan antrian yang panjang [9].

\section{Usulan Perbaikan}

Perbaikan sistem merupakan salah satu cara yang dibuat untuk memperbaiki sistem yang ada dengan melihat pada permasalahan dari sistem tersebut. Sistem yang memerlukan perbaikan adalah pada bagian stasiun pelayanan. Untuk itu diperlukan beberapa alternatif dalam sistem untuk membuat sistem tersebut lebih optimal yaitu dengan membuat beberapa skenario pada process analyzer. Beberapa skenario perbaikan sistem antara lain :

1. Skenario 1, yaitu terdapat 1 stasiun pelayanan. Skenario 1 menunjukkan keadaan yang ada di rumah makan saat ini.

2. Skenario 2 , yaitu usulan perbaikan dengan penambahan 1 stasiun pelayanan, sehingga terdapat 2 stasiun pelayanan pada sistem antrian.

3. Skenario 3, yaitu usulan perbaikan dengan penambahan 2 stasiun pelayanan, sehingga terdapat 3 stasiun pelayanan pada sistem antrian. 
Process analyzer alat yang mendukung dalam mengevaluasi alternatif yang disajikan oleh eksekusi model untuk membuat, menjalankan dan membadingkan skenario simulasi yang berbeda, dengan demikian dapat diamati efek dari skenario yang telah diatur sebelumnya.

Hal ini berguna untuk pengembangan model simulasi, serta pembuatan keputusan dimana tidak dikenal dengan model, namun akrab disebut dengan menangani solusi model simulasi, dan process analyzer dapat untuk menentukan skenario yang optimal.

Berdasarkan perbandingan hasil skenario perbaikan 1, 2, dan 3 yang telah dirancang dan dijalankan dengan bantuan process analyzer software ARENA 10.0 pada hari Senin sampai Jum'at jam 14.00-16.00 dan 18.00-22.00, Sabtu jam 16.00-22.00 dan Minggu jam 14.00-22.00 dipilih skenario 2 dikarenakan penurunan jumlah antrian yang optimal. Pada skenario 2 jumlah number out dengan number in memiliki selisih yang kecil, dengan Queue Waiting Time yang lebih singkat dibandingkan kondisi sebelumya, Queue Number Inqueue, tingkat Utilization dan Work In Process mengalami penurunan juga, dimana nilai Queue Waiting Time berkisar antara 0-18 detik, nilai Queue Number Inqueue 1 orang, nilai Utilization berkisar antara 0.37-0.68 \% dan nilai Work In Process berkisar antara 1-5 orang pada hari Senin sampai Jum'at jam 14.00-16.00, 18.00-20.00 dan 20.00-22.00, Sabtu jam 16.00-22.00 dan Minggu jam 14.00-22.00.

Pada skenario 2 mengasumsikan penambahan satu fasilitas stasiun pelayanan. Maka model antrian yang cocok adalah Multi Channel-Single Phase (M/M/2) ; (FCFS) dimana terdapat dua jalur antrian dengan dua fasilitas stasiun pelayanan pada hari Senin sampai Jum'at jam 14.00-16.00 dan 18.00-22.00, Sabtu jam 16.00-22.00 dan Minggu jam 14.00-22.00.

Pada gambar 6 menggambarkan mekanisme sistem antrian usulan perbaikan, yang terjadi dimulai dari pelanggan yang datang memasuki waiting line (garis tunggu antrian), lalu pelanggan memilih salah satu stasiun pelayanan untuk mendapatkan pelayanan. Disiplin antrian yang digunakan adalah first come first served, dimana didalam sistem ini pelanggan yang datang lebih dahulu akan mendapatkan giliran pelayanan terlebih dahulu dan model antrian yang digunakan Multi ChannelSingle Phase (M/M/2) ; (FCFS).

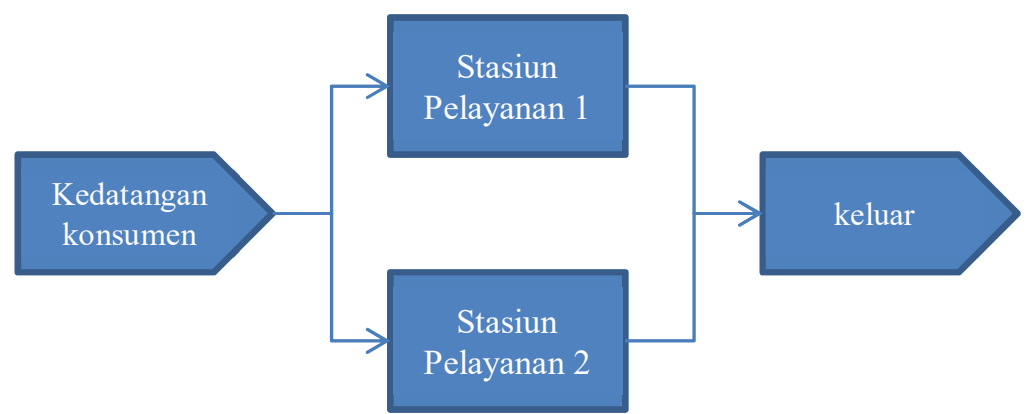

Gambar 5. Usulan hasil perbaikan process analyzer

\section{Kesimpulan}

Hasil evaluasi kinerja sistem antrian stasiun pelayanan Rumah Makan sebagai berikut:

1. Rata-rata kedatangan konsumen pada kondisi sepi jam 12.00-14.00,16.00-18.00 dan 22.0024.00, ramai jam 14.00-16.00, 18.00-22.00 dan jam 16.00-18.00 pada hari Sabtu dan Minggu.

2. Pada kondisi ramai antrian sangat tinggi, maka di perlukan perbaikan sistem pada stasiun pelayanan dengan membuat skenario 1,2 dan 3 dengan bantuan process analyzer software ARENA 10.0

3. Berdasarkan hasil beberapa skenario yang telah dirancang dan dijalankan dengan bantuan process analyzer software ARENA 10.0 dipilih skenario 2.

4. Pada skenario 2 mengasumsikan penambahan satu fasilitas stasiun pelayanan. Maka model antrian yang cocok adalah Multi Channel-Single Phase (M/M/2) ; (FCFS) dimana terdapat fasilitas 2 stasiun pelayanan pada kondisi ramai jam 14.00-16.00, 18.00-22.00 dan jam 16.00- 
Jurnal Teknologi dan Manajemen Industri, Vol. 4 No. 1, Februari 2018

Pascasarjana Institut Teknologi Nasional Malang

18.00 pada hari sabtu dan minggu. Penambahan stasiun digunakan hanya pada kondisi ramai saja.

\section{Daftar Referensi}

[4] Siagian, P. 1987. Penelitian Operasional Teori dan Praktek. Jakarta: Universitas Indonesia Press.

[5] Malau, H. 2017. Manajemen Pemasaran Teori dan Aplikasi Pemasaran Era Tradisional Sampai Era Modernisasi Global. Bandung: Alfabeta.

[3] Haming M, Ramlawati, Suriyanti \& Imaduddin. 2007. "Operations Research Teknik Pengambilan Keputusan Optimal". Jakarta:Bumi Aksara.

[4] Mussafi, M. 2015. "Pemodelan Sistem Antrian Multi Channel Jasa Teller Pada Bank Syariah Di Yogyakarta Untuk Meningkatkan Kinerja Perusahaan". Admathedu. Vol. 5, No.2.

[5] Haming, M., Ramlawati., Suriyanti \& Imaduddin. 2007. "Operations Research Teknik Pengambilan Keputusan Optimal". Jakarta:Bumi Aksara.

[6] Kelton. D., Sadowski. R \& Sadowski. D. 2002. "Simulation With Arena". Second Edition. McGraw-Hill.

[7] William J .2012. "Operations Management". Eleventh Edition. New York. McGraw-Hill/Irwin

[8] Sugiarto, F \& Buliali, L. 2011. "Implementasi Simulasi Sistem Untuk Optimasi Proses Produksi Pada Perusahaan Pengalengan Ikan". Jurnal Teknik Industri ITS. Vol. 1

[9] Iksan. 2006. "Merekomendasi Tambahan Dermaga Pelabuhan III Cabang Tanjung Perak Surabaya dengan Analisis Simulasi Sitem Antrean Kapal Barang". Jurnal Sistem Teknik Industri. Vol. 7, No. 2, hlm. 33-42. 